\title{
Analysis of Validity and Reliability of the Adapted Portuguese Version of Antonovsky's Sense of Coherence Questionnaire Among Nursing Professionals
}

\author{
Denise Rodrigues Costa Schmidt ${ }^{1}$ \\ Rosana Aparecida Spadoti Dantas²
}

\begin{abstract}
This methodological study aimed to evaluate the construct validity and reliability of the Brazilian-Portuguese version of Antonovsky's Sense of Coherence Questionnaire (ASCQ) among nursing professionals. The study included 211 professionals who worked in the surgical wards of eleven hospitals in a city in the interior of the State of Paraná-Brazil. The majority of participants were female (86.7\%), with a mean length of service of 9.3 $(S D=8.0)$ years. Construct validity was evaluated using Pearson correlation tests between the measures of sense of coherence and correlated constructs, obtaining strong negative correlations between sense of coherence and anxiety $(r=-0.53)$ and sense of coherence and depression ( $r=-0.61$ ). Internal reliability, assessed by Cronbach's alpha, obtained an acceptable value of 0.87. The Brazilian-Portuguese version of ASCQ maintained the psychometric properties of the original scale when used with nursing professionals.
\end{abstract}

Descriptors: Nursing; Validity of Tests; Reproducibility of Results.

\footnotetext{
${ }^{1}$ RN, Ph.D. in Nursing, Hospital Universitário de Londrina, PR, Brazil. E-mail: denisebeto@terra.com.br.

2 RN, Free Lecture, Associate Professor, Escola de Enfermagem de Ribeirão Preto, Universidade de São Paulo, WHO Collaborating Centre for Nursing Research Development, SP, Brazil. E-mail: rsdantas@eerp.usp.br.
}

Corresponding Author:

Denise Rodrigues Costa Schmidt

Hospital Universitário de Londrina. Centro Cirúrgico

Rua Robert Koch, 60

Vila Operária

CEP: 86038-440 Londrina, PR, Brasil

E-mail: denisebeto@terra.com.br 


\title{
Análise da validade e confiabilidade da versão adaptada para o português do Questionário de Senso de Coerência de Antonovsky, entre profissionais de enfermagem
}

Este é um estudo metodológico cujo objetivo foi avaliar a validade de constructo e a confiabilidade da versão brasileira do Questionário de Senso de Coerência de Antonovsky (QSCA), entre profissionais de enfermagem. Participaram do estudo 211 profissionais que atuavam nos blocos cirúrgicos de onze hospitais, de uma cidade do interior do Paraná, Brasil. A maioria dos participantes era do sexo feminino $(86,7 \%)$, com tempo médio de atuação de $9,3(\mathrm{dp}=8,0)$ anos. A validade de construto foi avaliada com testes de correlação de Pearson entre as medidas do senso de coerência e de construtos correlatos, obtendo correlação inversa e forte entre senso de coerência e ansiedade $(r=-0,53)$ e senso de coerência e depressão $(r=-0,61)$. A confiabilidade, avaliada pelo alfa de Cronbach, obteve valor aceitável de 0,87. A versão adaptada para o português do QSCA manteve as propriedades psicométricas da escala original, quando utilizada em profissionais de enfermagem.

Descritores: Enfermagem; Validade dos testes; Reprodutibilidade dos Testes.

\section{Análisis de validez y confiabilidad de la versión adaptada para el portugués del Cuestionario de Sentido de Coherencia de Antonovsky entre profesionales de enfermería}

\begin{abstract}
Estudio metodológico cuyo objetivo fue evaluar la validez de constructo y la confiabilidad de la versión brasileña del Cuestionario de Sentido de Coherencia de Antonovsky entre profesionales de enfermería. Participaron del estudio 211 profesionales que actuaban en los centros quirúrgicos de once hospitales de una ciudad del interior de Paraná, Brasil. La mayoría de los participantes era del sexo femenino $(86,7 \%)$, con tiempo promedio de actuación de 9,3 (D.E.=8,0) años. La validez de constructo fue evaluada con pruebas de correlación de Pearson entre las medidas del Sentido de Coherencia y de constructos correlacionados, obteniendo correlación inversa y fuerte entre Sentido de Coherencia y ansiedad $(r=-0,53)$ y Sentido de Coherencia y depresión $(r=-0,61)$. La confiabilidad, evaluada por el alfa de Cronbach, obtuvo valor aceptable de 0,87. La versión adaptada para el portugués del QSCA mantuvo las propiedades psicométricas de la escala original cuando utilizada en profesionales de enfermería.
\end{abstract}

Descriptores: Enfermería; Validez de las Pruebas; Reproducibilidad de Resultados.

\section{Introduction}

Antonovsky's salutogenic model(1) has been considered in the health literature as a new approach for the evaluation of individuals with chronic health conditions or belonging to specific groups such as the elderly, adolescents, pregnant women, children and workers from different areas. The focus is on the resources of coping rather than the stressors ${ }^{(1)}$. The sense of coherence, the key construct of this theory, is proposed to explain successful strategies for coping with stress. It is a global orientation that expresses the capacity of individuals to trust that, in their life, the stimulus originating from the internal and external environments are structured, predictable and explicable (comprehensibility); the resources are available so that they can meet the demands imposed by these stimuli (manageability), and that those demands are changes, worthy of investment and engagement (meaningfulness). Comprehensibility, Manageability and Meaningfulness are the three components that form the sense of coherence ${ }^{(2)}$. 
Stress has been associated with the presence of occupational diseases in several areas, among them nursing. In a study performed with nurses who worked in intensive care units, the authors concluded that the presence of stress was associated with job dissatisfaction and with the symptoms related to cardiovascular, digestive tract and musculoskeletal alterations ${ }^{(3)}$.

To evaluate the sense of coherence of nursing professionals in Brazil can be an important tool for the determination of managerial policies aimed at promoting the adjustment of workers to the workplace, identifying those that have a greater ability to cope with the stress present in the workplace. For this evaluation it is necessary to have available for our culture the instrument created to evaluate the sense of coherence and titled by the author as the Orientation to Life Questionnaire reported in the literature as Antonovsky's Sense of Coherence Questionnaire (ASCQ). This instrument was recently adapted and validated for the Portuguese language among heart patients ${ }^{(2)}$, and has been used among workers in different occupations ${ }^{(4)}$, among teachers ${ }^{(5)}$ and nursing professionals ${ }^{(6-7)}$ in other countries, however, in Brazil it has still not yet been applied among nursing staff.

Construct validity is one of the most important ways to evaluate the psychometric characteristics of an instrument, although it is the most complex and difficult to be determined. An instrument with good construct validity ensures the evaluation of the theory or hypothesis under investigation, being related to the ability of the instrument to confirm the expected hypothesis $^{(8)}$. The construct validity of the BrazilianPortuguese version of ASCQ (29 items) was investigated by means of convergent validity. To evaluate this validity the literature recommends the assessment of correlations between similar constructs( ${ }^{(8)}$, thus, the sense of coherence has been associated with depression alone $e^{(2,6,9-11)}$ and with depression together with anxiety ${ }^{(12-13)}$. There are indications that a strong sense of coherence would have a mediator effect between hostility and depressive symptoms ${ }^{(10)}$, while a low sense of coherence would be associated with an increased prevalence of depression ${ }^{(9)}$ and anxiety ${ }^{(12)}$. Therefore, validated instruments to measure constructs such as depression, anxiety and self-esteem, may be used to evaluate the convergent validity of instruments such as the ASCQ.

The following hypotheses was established to test the construct validity: 1 - There is divergent correlation (negative) of moderate to strong intensity between the total measurement of ASCQ and the measurement of anxiety, evaluated by the Anxiety subscale of the Hospital Anxiety and Depression Scale (HADS-A). 2 There is divergent correlation (negative) of moderate to strong intensity between the total measurement of ASCQ and the measurement of depression, evaluated by the Depression subscale of the Hospital Anxiety and Depression Scale (HADS-D).

The aims of this study were to evaluate the convergent construct validity and the internal reliability of the Brazilian-Portuguese version of the ASCQ and to verify the presence of the ceiling effect and floor effect when used with nursing professionals.

\section{Method}

\section{Design and setting}

This was a methodological study, part of an extended project which investigated physical and mental health and quality of life at work, performed with nursing professionals who worked on the surgical ward.

The study was conducted in 11 surgical wards of the city of Londrina - Paraná, Brazil and was approved by the Bioethics and Ethics in Research Committee of the Irmandade Santa Casa of Londrina, Bioiscal, under number 235/06, in accordance with the guidelines of Resolution 196/96 of the National Health Council/MS.

\section{Population}

The study population consisted of 340 professionals of the nursing staff of the Surgical Center and/or Center of Materials and Sterilization of 11 hospitals in the city of Londrina, which permitted the data collection. The study participants were 211 (66.8\%) nursing staff (nurses, technicians, auxiliaries and nursing attendants) who agreed to participate by signing the terms of free prior informed consent and returning the completed data collection instrument to the researchers.

\section{Data collection instrument}

The data collection instrument consisted of sociodemographic and professional data, through the adapted Brazilian-Portuguese version of $\mathrm{ASCQ}^{(2)}$ and through the adapted to Portuguese version of the Hospital Anxiety and Depression Scale (HADS)(14).

The ASCQ is a closed and systematized instrument containing 29 items that evaluate a single construct, the sense of coherence. According to its author, in the composition of the sense of coherence there is the presence of the components of comprehensibility (11 items), manageability (10 items) and meaningfulness 
(eight items)(1). Conforming to the author's guidance, these components should not be evaluated separately as subscales of ASCQ as the instrument is unidimensional and evaluates a single construct, sense of coherence. This unidimensionality has been confirmed by principal component analysis performed in several studies ${ }^{(1-2,15-16)}$. The responses to the items are obtained by a seven-point scale, with values ranging from one to seven, where the value seven represents the highest sense of coherence and one the weakest. Before calculating the total score of the scale, the 13 items that are scored in reverse were recoded, i.e. the value seven (7) was transformed into one (1), six (6) into two (2) and so on, as directed by the author of the questionnaire ${ }^{(1)}$. The possible score for the scale varies from 29 to 203, with higher values signifying a greater sense of coherence of the individual(1).

To evaluate anxiety and depression, the version adapted and validated for Brazilian-Portuguese ${ }^{(14)}$ of the Hospital Anxiety and Depression Scale (HADS)(17) was opted for. These measures were selected based on the literature that has shown that depression and anxiety are negatively associated with the measurement of sense of coherence ${ }^{(2,12-13)}$. The HADS contains 14 multiple-choice questions, divided into two subscales: anxiety (HADS-A) and depression (HADS-D), with seven items each. Each item has a score from zero to three and the overall scores for each subscale range from zero to 21 . Higher values indicate more symptoms of anxiety or depression ${ }^{(17)}$.

\section{Semantic analysis and pre-test}

To evaluate the psychometric properties of the adapted version of ASCQ among the workers, the semantic analysis of the questionnaire was performed in April 2007 to verify that all items were understandable to the potential participants. Three nursing assistants and a nurse of one of the hospitals of the study participated in the semantic analysis. They were chosen at random and had no difficulties understanding the items, with the same wording and format of the version adapted to Portuguese being maintained. Next, a pretest was performed with 20 nurses of two hospitals in the study who responded to the instrument individually. As they presented no difficulties in comprehending or completing the instrument, the Brazilian-Portuguese version of ASCQ tested among cardiac patients ${ }^{(2)}$ was applied to the participants of this study.

\section{Data collection}

Data were collected from May to November 2007, through the questionnaires that were delivered, by hand by one of the researchers, to the potential respondents in sealed envelopes, which helped to ensure the anonymity of participants.

\section{Statistical analysis}

The data were processed and analyzed using the software program Statistical Package for the Social Sciences (SPSS) version 15.0 for Windows. Descriptive analysis was performed for all variables.

For the evaluation of the convergent construct validity of the adapted to Portuguese version of ASCQ Pearson's correlation tests were performed between the measures of sense of coherence, anxiety and depression. To classify the strength of correlation between variables, values close to 0.30 were consider satisfactory, from 0.30 to 0.50 of moderate magnitude, above 0.50 of high magnitude and values below 0.30 of little value for the practice, even though statistically significant ${ }^{(18)}$. The choice of this classification differs from the interpretation commonly used by authors as, in this case, correlations between subjective construct measures that cannot be directly observed by the researcher were being investigated, which is common in the social sciences ${ }^{(18)}$.

For the analysis of the reliability of the BrazilianPortuguese version of $A S C Q$, with regard to the internal consistency of its items, the Cronbach alpha was calculated. The reliability of the measures of anxiety and depression was also evaluated and although there is no minimum threshold for a reliability coefficient to be considered adequate for all purposes, it is understood that, in the absence of other flaws, he higher the coefficient, the more reliable the instrument ${ }^{(8)}$. Therefore, values above 0.70 were considered appropriate for this study. The level of significance adopted for testing the hypotheses of the study was 0.05 .

The existence of floor and ceiling effects are observed when more than $15 \%$ of participants make the choice of the lowest or highest possible score for the response scale, respectively ${ }^{(19)}$. This analysis is performed as an evaluation of the responsiveness of the instrument. Regarding the handling of missing data, the criteria was followed that establishes that only those participants who had $20 \%$ or more unanswered items in a given scale should be excluded from the sample(20). Given this criterion, participants who had responded to at least 24 items of the questionnaire were retained for the analysis of ASCQ. For these participants it was decided to substitute the missing data with the mean of their responses to the other items on the scale. 


\section{Results}

Among the 211 workers who participated in the study, $183(86.7 \%)$ were female, the majority married $(n=114,54.0 \%)$, with a mean age of 40 years $(S D=9.7)$ and complete high school education ( $n=123,58.3 \%)$. It was found that $31(14.7 \%)$ professionals were seeking additional training through undergraduate courses in progress. Among the $36(17.1 \%)$ graduate professionals, $16(7.6 \%)$ continued professional development through lato sensu $(n=15 ; 41.7 \%)$ and stricto sensu $(n=1 ; 2.8 \%)$ postgraduate courses. With respect to professional characteristics, $62.6 \%(n=132)$ were auxiliary nurses, $10.4 \%$ (22) were nurses, $12.8 \%$ (27) technicians and $13.3 \%$ (28) nursing attendants. The length of experience for the participants of this study presented a mean of 9.3 $(S D=8.0)$ years, ranging from two months to 32 years. The average weekly working hours presented a mean of $47.3(S D=16.0)$ hours, ranging from 20 to 90 hours of work. It was also noted that the majority of workers belonged to the public and philanthropic institutions $(n=123 ; 58.3 \%)$. The wage of $66.4 \%(n=140)$ of the professionals was one to three minimum wages, while only $7.1 \%$ (15) received more than seven minimum wages and $22.7 \%$ (48) of the professionals had two employment contracts.

Regarding the analysis of the lost data of ASCQ, eight workers were excluded, composed of three that did not answer all the items of the instrument and the others that did not answer between six and 16 items. The most frequent non-response item was item 11 (3.8\%) which inquires about future goals. The values of the unanswered items of the participants who obtained less than $20 \%$ of nonresponses were replaced by the mean of the participant's responses to the other items. Items $4,7,8,13,14,16$, $20,22,23$ and 27 were the items of the questionnaire that obtained most answers were directed to the value seven. Items 13 and 14 presented the highest frequency for this extreme of the scale, with $65.4 \%$ and $66.4 \%$, respectively, as can be seen in Table 1.

Table 1 - Distribution of frequencies of responses to the items of the Brazilian-Portuguese version of Antonovsky's Sense of Coherence Questionnaire (ASCQ) and of items not answered by the nursing professionals of the Surgery Unit, Londrina-PR, 2007

\begin{tabular}{|c|c|c|c|c|c|c|c|c|}
\hline ASCQ & Value $1(\%)$ & Value $2(\%)$ & Value $3(\%)$ & Value $4(\%)$ & Value $5(\%)$ & Value $6(\%)$ & Value $7(\%)$ & Not answered \\
\hline Item1 & 2.4 & 2.4 & 8.1 & 9.5 & 15.6 & 28.4 & 31.3 & 2.4 \\
\hline Item 2 & 3.3 & 6.2 & 11.8 & 11.8 & 18.5 & 14.7 & 30.8 & 2.8 \\
\hline Item 3 & 11.4 & 12.3 & 19.4 & 25.6 & 12.3 & 6.6 & 10.0 & 2.4 \\
\hline Item 4 & 8.1 & 3.3 & 8.5 & 8.1 & 10.4 & 20.9 & 38.9 & 1.9 \\
\hline Item 5 & 20.9 & 21.3 & 20.4 & 11.8 & 10.0 & 8.5 & 5.2 & 1.9 \\
\hline Item 6 & 16.1 & 24.2 & 19.0 & 12.8 & 10.0 & 11.8 & 3.8 & 2.4 \\
\hline Item 7 & 9.0 & 2.8 & 7.6 & 11.8 & 9.5 & 13.3 & 43.6 & 2.4 \\
\hline Item 8 & 1.4 & 1.4 & 1.4 & 3.3 & 10.4 & 20.9 & 58.8 & 2.4 \\
\hline Item 9 & 7.1 & 7.6 & 11.4 & 12.8 & 19.0 & 16.1 & 23.7 & 2.4 \\
\hline Item 10 & 29.9 & 12.8 & 12.3 & 13.7 & 13.3 & 7.1 & 9.0 & 1.9 \\
\hline Item 11 & 1.4 & 0.5 & 4.7 & 17.1 & 20.4 & 20.4 & 31.8 & 3.8 \\
\hline Item 12 & 1.4 & 3.8 & 10.9 & 12.8 & 18.0 & 23.7 & 26.5 & 2.8 \\
\hline Item 13 & 0.5 & 0.9 & 0.9 & 4.7 & 6.6 & 19.0 & 65.4 & 1.9 \\
\hline Item 14 & 0.9 & 1.9 & 2.4 & 5.2 & 9.0 & 11.4 & 66.4 & 2.8 \\
\hline Item 15 & 7.8 & 10.9 & 8.1 & 18.5 & 25.1 & 16.6 & 10.9 & 2.4 \\
\hline Item 16 & 1.9 & 0.5 & 2.8 & 10.9 & 12.8 & 29.4 & 39.3 & 2.4 \\
\hline Item 17 & 25.6 & 17.1 & 9.0 & 14.7 & 13.3 & 10.9 & 6.6 & 2.8 \\
\hline Item 18 & 4.3 & 6.2 & 9.0 & 14.2 & 16.1 & 19.4 & 28.0 & 2.4 \\
\hline Item 19 & 3.3 & 4.7 & 11.4 & 9.5 & 18.0 & 20.9 & 29.9 & 2.4 \\
\hline Item 20 & 0.9 & 3.3 & 4.3 & 4.7 & 11.4 & 21.3 & 51.2 & 2.8 \\
\hline Item 21 & 7.6 & 9.0 & 14.7 & 9.5 & 19.4 & 21.3 & 16.1 & 2.4 \\
\hline Item 22 & 1.4 & 0.5 & 3.3 & 5.7 & 10.9 & 21.3 & 54.5 & 2.4 \\
\hline Item 23 & 7.6 & 3.3 & 9.0 & 10.4 & 10.0 & 17.1 & 40.8 & 1.9 \\
\hline Item 24 & 10.0 & 6.6 & 12.3 & 17.1 & 15.6 & 16.1 & 19.4 & 2.8 \\
\hline Item 25 & 4.3 & 7.1 & 19.4 & 22.3 & 19.4 & 14.7 & 10.4 & 2.8 \\
\hline Item 26 & 10.9 & 6.2 & 11.8 & 22.3 & 17.1 & 14.7 & 14.7 & 2.4 \\
\hline Item 27 & 0.5 & 1.9 & 3.3 & 12.3 & 17.1 & 22.3 & 40.3 & 2.4 \\
\hline Item 28 & 0.9 & 5.7 & 5.7 & 11.8 & 10.0 & 25.6 & 37.4 & 2.8 \\
\hline Item 29 & 5.7 & 6.6 & 6.2 & 9.5 & 12.3 & 25.1 & 32.2 & 2.4 \\
\hline
\end{tabular}


The mean of ASCQ for the 203 nursing professionals of the SU who answered the questionnaire was 144.6 $(S D=22.6)$ and the median was 144 , which was higher than the median of the possible range between 29 and 203 , which is 116 . The score obtained ranged between 69 and 201, revealing that there were both professionals with low and high sense of coherence. Regarding the median of the items, values ranged from three (items 5 , 6,10 and 17) to seven (items 8, 13, 14, 20 and 22). The averages of the items ranged from 3.1 (item 5) to 6.4 (item 13), possible range from one to seven.

The presence of the floor and ceiling effects, i.e. a frequency greater than $15 \%$ of participants' responses at the lowest or the highest possible scores of the scale, respectively, was observed in some items. The floor effect was present in items 5, 6, 10 and 17 and the ceiling effect was observed in most items except for items 3,5 , $6,10,15,17,25$ and 26 . The internal consistency of the instrument was verified by Cronbach's alpha, obtaining a value of 0.87 , demonstrating the existence of this measure of reliability of the instrument in the population studied. The results related to the scale (HADS) used for the analysis of convergent validity with the measure of sense of coherence are presented in Table 2 .

Table 2 - Descriptive statistics and internal consistency of the subscales HADS-Anxiety and HADS-Depression among the nursing professionals of Surgical Wards. Londrina - PR, 2007

\begin{tabular}{lcccccc}
\hline \multicolumn{1}{c}{ HADS subscales } & No. of items & Cronbach's Alpha & Mean (SD) & Median & Possible range & Range obtained \\
\hline Anxiety & 7 & 0.79 & $6.3(3.7)$ & 6.0 & $0-21$ & $0-21$ \\
Depression & 7 & 0.77 & $5.2(3.3)$ & 5.0 & $0-21$ \\
\hline
\end{tabular}

The values of Cronbach's Alpha coefficients for the subscales HADS-anxiety and HADS-depression were above 0.70 , which indicates the reliability of the measures used to test the convergent construct validity of the BrazilianPortuguese version of ASCQ. To verify the convergent validity of sense of coherence evaluated by the instrument ASCQ among nursing staff, testing the correlation between the measure of sense of coherence and the measure of anxiety and depression, as assessed by HADS was opted for. In Table 3 the values of the correlation coefficients obtained between measures of ASCQ and HADS among nursing professionals of SU are presented.

Table 3 - Pearson correlations between the measurements obtained from Brazilian-Portuguese version of Antonovsky's Sense of Coherence Questionnaire (ASCQ) and from the Hospital Anxiety and Depression Scale. Londrina - PR, 2007

\begin{tabular}{lccc}
\hline \multicolumn{1}{c}{ Measures } & ASCQ & HADS-A & HADS-D \\
\cline { 2 - 4 } ASCQ & 1 & $-0.53^{*}$ & $-0.61^{*}$ \\
HADS - A & & 1 & $0.77^{*}$ \\
HADS - D & & & 1 \\
\hline
\end{tabular}

* level of significance of 0.01

With these results it was found that there was a strong negative correlation between the measurements obtained by ASCQ and the measures of anxiety and depression, i.e. ASCQ is positively ordered, higher values indicate a greater sense of coherence. The HADS-A and the HADS-D are also positively ordered and higher values indicate more symptoms of anxiety or depression. The negative correlation between the measure of sense of coherence with measures of anxiety and depression confirmed the hypotheses of this study.

\section{Discussion}

Descriptive analysis of data obtained from the application of ASCQ among nursing professionals showed a median of 144 and a mean of 144.6 $(S D=22.6)$. In this study no significant difference was observed between the mean and median values for the total measure of sense of coherence. The same was observed in the study of the adaptation of the instrument, in which the median and mean were very close. The median found among cardiac patients was 146.5 and the mean $143.2(S D=24.9)^{(2)}$. A similar result was found in a study ${ }^{(21)}$ among pharmacists, where the mean was $148.23(S D=20.22)$ and in a systematic review study(22), in which the 124 studies that used the version with 29 items of ASCQ obtained means for the sense of coherence between $100.5(S D=28.5)$ and $164.5(\mathrm{SD}=17.1)$.

Regarding the median of the items, the value to be obtained in this range should be four, however, the median values varied between 3.0 and 7.0. A similar result was found in a previous study ${ }^{(2)}$, where the median value ranged between one and seven. Ten 
of the 29 items of the questionnaire obtained a high frequency of responses directed toward the value of the seven of the scale, i.e. there was the presence of a ceiling effect(19). Items 13 and 14, which enquire about the view that the individual has about his life, presented a response frequency of $65 \%$ for this extreme of the scale, confirming that in this population there is a great tendency among respondents to mark the value seven of the questionnaire, as indicated by the literature ${ }^{(2,23)}$. In the study of the validation of the instrument, items 13 to 14 also obtained the highest frequency of responses to the value seven $(75 \%)^{(2)}$. The author of the original instrument has previously warned that one of the problems when using ASCQ is the tendency of some respondents to answer only with the extreme value of the response scale(23). Regarding the validity of the instrument in the population studied confirmation through semantic analysis of the instrument and convergent construct validity was sought. In relation to the reliability of the instrument the same was found by analyzing the internal consistency, measured by Cronbach's alpha.

Satisfactory results were obtained which indicate the maintenance of the construct validity and internal consistency of the Brazilian-Portuguese version of the ASCQ in the group of nursing staff. Specifically regarding Cronbach's alpha, the value of 0.87 was obtained, being higher than that found in the study of the adaptation of the questionnaire into Portuguese, which was $0.78^{(2)}$. Other studies using the 29 items version of ASCQ also present acceptable Cronbach's alpha values similar to the present study, namely $0.91^{(21)}, 0.70$ to $0.95^{(22)}$ and $0.82^{(24)}$.

Concerning the convergent construct validity, the values obtained by ASCQ were correlated with the measurements originated from the HADS-A and HADS-D. Presence of depression and anxiety has been strongly associated with a low level of sense of coherence ${ }^{(1-2,12,22)}$. The results obtained confirm the inverse correlation between these measures, since Pearson correlation coefficient values of $r=-0.53$ for the HADS-A and $r=-$ 0.61 for the HADS-D were obtained. Similar results were found by other authors when testing the construct validity between measures of sense of coherence and depression, where correlation values ranged from -0.45 to $-0.75^{(2,22)}$. Another study found correlations that ranged from moderate to strong magnitude between sense of coherence and the measures of anxiety and depression $(r=-0.28 \text { and } r=-0.73, p<0.01)^{(12)}$.

The evaluation of the sense of coherence has been used as an indirect measurement of the ability to face stress (coping) and also as a measure of the construct called resilience. The availability of this instrument for use in Brazilian nursing can be an important tool for studies on this theme.

\section{Conclusion}

The results obtained indicate the presence of adequate internal consistency and the presence of construct validity of the version of Antonovsky's Sense of Coherence Questionnaire adapted into BrazilianPortuguese when used in a group of nursing staff. This study allows the increase in the use of ASCQ among professionals of various areas of nursing and the subsequent comparison with studies conducted in other countries.

\section{References}

1. Antonovsky A. Unraveling the mystery of health. São Francisco: Jossey-Bass; 1987.

2. Dantas RAS. Adaptação cultural e validação do questionário de senso de coerência de Antonovsky em uma amostra de pacientes cardíacos brasileiros [tese livre-docência]. Ribeirão Preto: Escola de Enfermagem de Ribeirão Preto/USP; 2007.

3. Cavaleiro AM, Moura DF Júnior, Lopes AC. Stress in nurses working in intensive care units. Rev. Latino-Am. Enfermagem. 2008;16(1):29-35.

4. Kivimaki M, Eloviano M, Vahtera J, Nurmi JE, Feldt T, Keltikangas-Jarvinen $L$, et al. Sense of coherence and health: evidence from two cross-lagged longitudinal samples. Soc Sci Med. 2000 April; 50(4):583-97.

5. Harri M. The sense of coherence among nurses educators in Finland. Nurse Educ Today.1998; 18(3):202-12.

6. Tselebis A, Moulou A, Ilias I. Burnout versus depression and sense of coherence: study of Greek nursing staff. Nurs Health Sci. 2001; 3(2):69-71.

7. Leino-Loison K, Gien LT, Katajisto J, Vlimki M. Sense of coherence among unemployed nurses. J Adv Nurs. 2004; 48(4):413-22.

8. Urbina S. Fundamentos da testagem psicológica. Porto Alegre: Artmed; 2007. p. 121-212.

9. Buchi S, Sensky T, Alland S, Stoll T, Schnyder U, Klaghofer $R$, et al. Sense of coherence - a protective factor for depression in rheumatoid arthritis. J Rheumatol. 1998; 25(5):869-75.

10. Kivimaki M, Eloviano M, Vahtera J, Nurmi JE, Feldt $T$, Keltikangas-Jarvinen $L$, et al. Sense of coherence as a mediator between hostility and health: seven-year prospective study on female employees. J Psychosom Res. 2002; 52(4):239-47. 
11. Pallant J, Lae L. Sense of coherence, well-being, coping and personality factors: further evaluation of the sense of coherence scale. Pers Individ Dif. 2002; 33:39-48.

12. Schnyder $U$, Büchi $S$, Sensky $T$, Klaghofer R. Antonovsky's sense of coherence: trait or state? Psychother Psychosom. 2000; 69(6):296-302.

13. Sjöström H; Langius-Eklöf $A$; Hjertberg R Well-being and sense of coherence during pregnancy. Acta Obstet Gynecol Scand. 2004; 83(12):1112-8.

14. Botega NJ, Pondé MP, Medeiros P, Lima MG, Guerreiro CAM. Validação da escala hospitalar de ansiedade e depressão (HAD) em pacientes epiléticos ambulatoriais. J Bras Psiquiatria. 1998; 47(6):285-9.

15. Frenz A, Carey M, Jorgensen R, Psychometric evaluation of Antonovsky's Sense of Coherence Scale. Psychological assessment. 1993;5:145-53.

16. Soderhamn O, Holmgren L. Testing Antonovsky's sense of coherence (SOC) scale among Swedish physically active older people. Scand J Psychol. 2004; 45(3):215-21.

17. Zigmond AS, Snaith RP. The hospital anxiety and depression scale. Acta Psych Scand. 1983; 67(6):361-70.

18. Ajzen I, Fishbein M. Understanding attitudes and predicting social behavior. New Jersey: Prentice-Hall; 1998.

19. Terwee, CB, Bot SDM, Boer MR, Windt DAWM, Knol $\mathrm{DL}$, Dekker J et al. Quality criteria were proposed for measurement proprieties of health status questionnaires. J Clin Epidemiol. 2007; 60(1):34-42.

20. Cohen J, Cohen P. Applied multiple regression/ correlation for the behavioral sciences. 2. ed. Hillsdale: Lawrence Erbaum; 1983.

21. Rothmann S, Scholtz PE, Fourie M, Rothmann JC. The relationship between individual variables and work-related outcomes, 2002. [acesso 16 julho 2008]. Disponível em: http//www.content.apa.org/journals/fsh.

22. Eriksson M, Lindström B. Validity of Antonovsky's sense of coherence scale: a systematic review. J Epidemiol Comm Health. 2005; 59(6):460-6.

23. Antonovsky, A. The structure and proprieties of the Sense of Coherence Scale. In: McCubbin HM, Thompson EA, Thompson AI, Fromer JE. Stress, Coping, and Health in families Sense of Coherence and Resiliency. California: Sage; 1998. p. 21-40.

24. Larson G, Kallenberg KO. Sense of coherence, socioeconomic conditions and health. Eur J Public Health. $1996 ; 6(3): 175-80$.

Received: Nov. $10^{\text {th }} 2009$

Accepted: Ago. 25 2010 